\title{
IS RADIOFREQUENCY ABLATION IN CONJUNCTION WITH VERTEBRAL AUGMENTATION AN EFFECTIVE OPTION IN PAINFUL SPINAL METASTASIS?
}

\author{
(1) Ömer Faruk Kılıçaslan'1, (1) Ayșen Kılıçaslan², (1) Vugar Nabi1 , (1) Serdar Akalın¹ \\ ${ }^{1}$ University of Health Sciences Turkey, Antalya Training and Research Hospital, Clinic of Orthopaedics and Traumatology, Antalya, Turkey \\ 2University of Health Sciences Turkey, Antalya Training and Research Hospital, Clinic of Pathology, Antalya, Turkey
}

\begin{abstract}
Objective: Patients with metastatic tumors are most frequently expressed with painful spinal lesions. However, effective palliative treatment is still controversial. The aim of this study is the assessment of the efficacy and safety of vertebral augmentation in conjunction with radiofrequency ablation (RFA) of painful spinal metastases.

Materials and Methods: Twenty-six patients with metastatic spine tumors treated with RFA in conjunction with cement augmentation between June 2014 and December 2019 were retrospectively analyzed. The patients were followed up for an average of $25.2 \pm 13.8$ months. Evaluation of efficacy is performed based on tumor pain, pain disability, functional activities, quality of life, neurological status, and tumor progression. Reliability evaluation was made based on complications and side effects.

Results: The mean age was $64.4 \pm 12.6$ years. The female to male ratio was 14:12. RFA with augmentation was successfully performed on all patients. No major complications developed in these patients. Primary tumors were observed to be more breast (38\%), renal (23\%) and multiple myeloma (12\%). Visval analogue Scale scores decreased after the procedure and improvement continued in every period of follow-up (from $8.2 \pm 1$ months preoperatively to $3.5 \pm 1.6$ months postoperatively $p<0.005$ ). The patients discontinued painkiller use after one month. On the Oswestry dysability scale score, significant improvement was observed in the first month $(41.8 \pm 15.1$ vs $82.6 \pm 9.1, p<.005)$. Tumor progression was observed in different regions in 10 patients and we lost those patients in the follow-up.

Conclusion: In painful spinal metastases with preserved posterior wall and pedicle integrity, the combination of RFA in conjunction with vertebroplasty can be safely implemented for pain palliation and local tumor control.

Keywords: Spine, neoplasm metastasis, palliative, radiofrequency ablation, vertebral augmentation
\end{abstract}

\section{INTRODUCTION}

Spine involvement is known to be about $40 \%$ in patients with the metastatic bone disease ${ }^{(1)}$. Clinically, this problem, which may lead to severe pain, pathological fractures and neuromuscular dysfunction, causes the patient to become immobile and leads to a deterioration in the quality of life ${ }^{(2-4)}$. Palliative treatment in these patients poses major challenges and calls for a comprehensive, multidisciplinary approach ${ }^{(5)}$. In painful metastatic lesions, radiofrequency ablation (RFA) therapy has begun to be used as a micro-invasive process, which disrupts intraosseous nerve fibres, reduces lesion volume, reduces osteoclastic activity, and prevents pain transmission by disrupting tumor cells that produce nerve stimulating cytokines ${ }^{(6,7)}$.

At the same time, the combined use of cement to increase the resistance of the spine to compressive loads can increase the quality of life of the patients and prevent complications that may lead to neurological damage resulting from pathological fractures ${ }^{(8,9)}$.

This study aimed to investigate the effect of combined treatment of percutaneous RFA and vertebral augmentation on the quality of life of patients with spinal metastasis.

\section{MATERIALS AND METHODS}

After the approval of the University of Health Sciences Turkey, Antalya Training and Research Hospital Clinical Research Ethics Committee (date: 22.12.2020, number: 20/23), the data of patients who underwent RFA and vertebral augmentation for painful metastatic spine disease in our clinic between 2014 and 2019 were retrospectively analyzed. The database included the patien's age, gender, primary tumor histology, level of the treated spine, the location and volume of the lesion in the involved spine, the number and duration of ablations performed 
and the patient's history of radiotherapy in the previous six weeks. After a complete description of the study to the subjects, written informed consent was obtained. The Declaration of Helsinki were taken into account during the present study.

Patients undergoing RFA and vertebroplasty were selected according to the decision of the council consisting of a spine surgeon and medical oncologist. Patients who have pain that leads to decreased quality of life and could not be controlled with conventional analgesics, localized tumors in two or three adjacent vertebrae and persistent and recurrent pain despite radiation therapy were included in the study. Patients with osteoblastic lesions, spinal instability and cord compression due to metastatic mass were excluded from the study.

After the patients were turned to the prone position under superficial sedation, the surgical area was disinfected with Betadine solution and prophylactic antibiotic treatment was administered before and after the procedure (cefazoline IV, $1 \mathrm{~g} \times$ 4/12 hours). Local anaesthetic infiltration was applied, starting from the skin area, including the vertebral periosteum to be treated. The unilateral or bilateral transpedicular guide was placed under the guidance of fluoroscopy (Figure 1$)^{(10)}$. A transpedicular biopsy was performed before performing RFA as a routine protocol and the results were recorded on the patient chart (Figure 2). After the procedure, analgesic treatment was ordered by the routine protocol of the clinic. Patients were

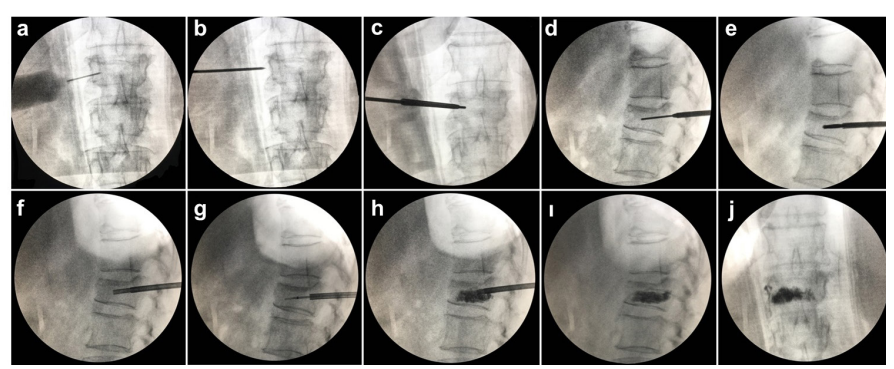

Figure 1. Percutaneous RFA and vertebroplasty procedure. The anteroposterior and lateral projection on fluoroscopy shows the position of the needles ( $a, b, c, d, e, f)$, vertebral lesions treated with RFA (g); distribution of the cement through the entire vertebral body $(h, i, j)$

RFA: Radiofrequency ablation
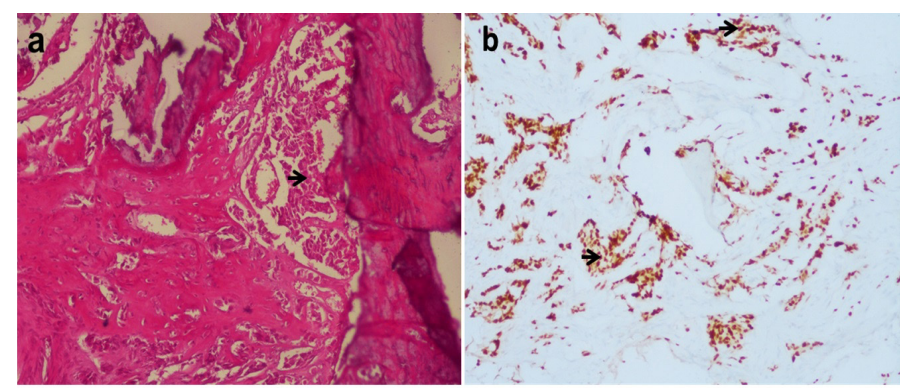

Figure 2. Breast tumor cells with pleomorphic, large hyperchromatic nucleous, eosinophilic cytoplasm (black arrow), consisting of small acinar structures in bone and chondroid matrix. H\&E,10x (a) and ER nuclear positive, 10x (b) evaluated at the first week and the first, third, and sixth months in the postoperative period with the Visual analogue scale (VAS) and the Oswestry disability index (ODI) for the assessment of the quality of life, and as well as with an magnetic resonance imaging in terms of recurrence.

\section{RESULTS}

Data of 26 patients with painful spinal metastases who met the inclusion criteria were retrospectively analyzed. The mean age of the patients was $64.4 \pm 12.6$ years. Female to male ratio was 14:12. The demographic characteristics of the patients are presented in Table 1 . The most common primary tumor was Breast Ca, followed by Renal Ca and Multiple Myeloma. It was observed that the treated metastatic spine disease was in the thoracic region in $35 \%$ of the cases and the lumbar

Table 1. Demographic data and function outcome scores of the patients

\begin{tabular}{ll}
\hline Patients & Data \\
\hline Age (year) & $64.4 \pm 12.6$ \\
\hline Gender & \\
\hline Female & 14 \\
\hline Male & 12 \\
\hline Primary lesion & \\
\hline Breast & 10 \\
\hline Renal cell & 6 \\
\hline Multiple myeloma & 3 \\
\hline Gastric Ca & 2 \\
\hline Lung & 2 \\
\hline Liver & 2 \\
\hline Colon & 1 \\
\hline Lymphoma & 1 \\
\hline Cervix Ca & 1 \\
\hline Treated vertebral level & \\
\hline One & 22 \\
\hline Two or more & $4.6 \pm 1.0$ \\
\hline Lentgh of operation (minute) & $42.9 \pm 11$ \\
\hline Hospital stay (days) & $1.3 \pm 1.4$ \\
\hline Follow-up (month) & $25.2 \pm 13.8$ \\
\hline VAS scores & $3.6 \pm 1.6$ \\
\hline Preoperative & $3.7 \pm 1.3$ \\
\hline Postoperative first day & \\
\hline Postoperative first month & \\
\hline Postoperative three month & \\
\hline Postoperative six month & \\
\hline ODI & \\
\hline Preoperative & \\
\hline Postoperative one month & \\
\hline VAS: Visual analogue scale, ODI: Oswestry scale, Ca: Cancer \\
\hline
\end{tabular}


region in $65 \%$. RFA with vertebroplasty was successfully performed on all patients (Figure 3 and 4). Cement leakage was not observed. No other complications occurred during the procedure. There was a significant decrease in the VAS scale after the procedure, indicating a decrease in pain intensity and a significant difference in each post-procedure compared to the pre-procedure. The evaluation of the ODI at 1 month compared with before the procedure also showed significant improvement in all domains (Table 1). Analgesic doses were reduced in all patients 24 hours after the procedure, and one month later all patients had greatly improved their quality of life and stopped the analgesic because there was no significant pain that would affect functional activity. Nine of the 26 patients (34.6\%) enrolled in the study had tumor progression in different regions, and all of these patients died during a mean follow-up period of 19 months (range: 6-40 mos.). No local recurrence was observed in the radiographic examinations performed during the controls of the patients.

\section{DISCUSSION}

In this study, we retrospectively evaluated the efficacy and safety of RFA in conjunction with vertebral augmentation in pain palliation in painful spinal metastases. As a result of the evaluation, we determined that this treatment approach is effective and safe. During the follow-up period, no recurrences, major side effects, or complications were observed, and

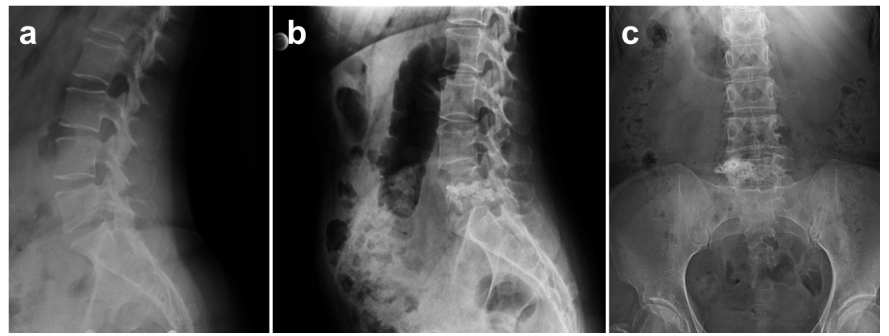

Figure 3. A 46-year-old female patient with metastatic breast cancer to the L5 vertebra. Preoperative (a) and 12-month follow-up radiographs (b, c). Patient's pain decreased from $9 / 10$ to 4/10 after treatment and at the last follow-up
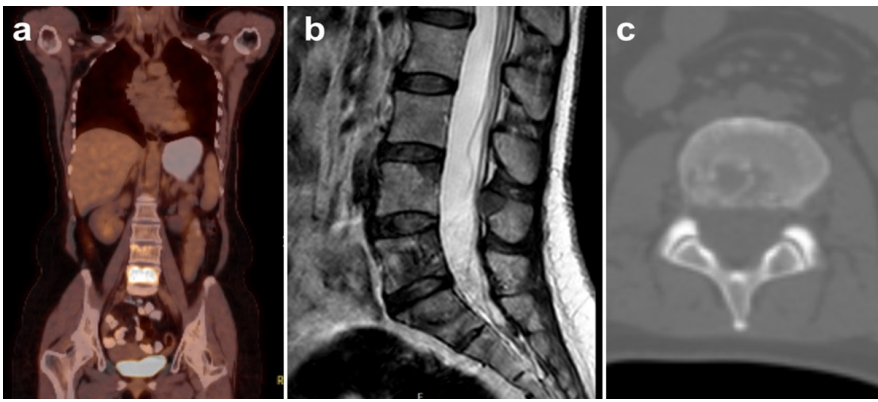

Figure 4. Preoperative PET (a) and sagittal T1-weighted MR imaging showing the level (L5) of spinal metastasis (b), Preoperative axial CT showing the osteolytic metastatic tumor (c)

MR: Magnetic resonance, CT: Computed tomography, PET: Positron emission tomography secondary surgical interventions were not required. All pain was effectively controlled using only analgesics. The patients' quality of life improved. This study supported the use of RFA in conjunction with vertebroplasty as a viable, minimally invasive spinal approach for the treatment of patients with thoracolumbar vertebral metastasis. Our findings were supported by the literature.

Since RFA was first carried out of in conjunction with vertebroplasty there has been an increase in the literature investigating its role in painful spinal metastases ${ }^{(11)}$. It has been emphasized that this treatment approach can be used not only for pain palliation but also for local tumor control. In the guidelines published by the Metastatic Spine Working Group, patients with asymptomatic spinal metastases, uncomplicated painful metastases, and stable pathological vertebral fractures and with a life expectancy of more than six months can safely have RFA and vertebral augmentation performed for pain palliation and local tumor control ${ }^{(12)}$. In their study, Hoffman et al.(13) demonstrated that the application of vertebral augmentation with RFA had a $100 \%$ pain-relieving effect within the first 24 hours, and they found that the combined procedure had a synergistic effect. It was shown that VAS scores significantly decreased from 7.2/10 before the procedure to $3.4 / 10$ after the procedure ${ }^{(13)}$. Reyes et al. ${ }^{(14)}$ reported significant improvement in palliation of pain and level of function with combined RFA and vertebroplasty in their multicenter retrospective study of 49 patients with 72 painful vertebral metastases. In the studies, the most important common findings, apart from pain palliation, was that no treatment-related complications occurred during the procedure and follow-up.

In research studies, many reasons have been shown why RFA should be performed before vertebroplasty ${ }^{(15)}$. The most often reason given for this sequence is reducing the potential for distal metastasis in the venous system by changing the location of tumor cells, preventing complications associated with embolization by causing thrombosis of the vertebral venous plexus, and ensuring a more equal distribution of cement to provide better stability to the spine ${ }^{(16)}$. In addition, radiographic local control rates of combined RFA and vertebroplasty were reported as $89 \%(41 / 46)$ and $70 \%(21 / 30)$ after three months and one year, respectively ${ }^{(17)}$.

Nakatsuka et al.(18) reported serious complications such as paraparesis and severe pain in up to $25 \%$ of patients after the RFA treatment for spinal metastases, but they stated that most of the patients they treated had a posterior wall and pedicle invasion and as a result related complications occurred at a high rate ${ }^{(18)}$. They reported that the symptoms disappeared during the follow-up. In our study, we did not see any major complications in the patients, since the spinal metastases did not destruct the posterior wall and the pedicles. We observed a significant improvement in pain and quality of life using the VAS and ODI scores that can accurately evaluate the refractory pain and quality of life of the patients. A limited number of patients, the absence of a control group, and a short follow-up 
period are the limitations of our study. However, the emergence of many metastases in the follow-up of the patients poses a serious difficulty in the long-term follow-up to determine the recurrence and survival of these patients.

\section{CONCLUSION}

RFA with combined cement injection is safe and effective in the palliative treatment of patients with painful metastatic spine tumors.

\section{Ethics}

Ethics Committee Approval: The study approved by University of Health Sciences Turkey, Antalya Training and Research Hospital Clinical Research Ethics Committee (date: 22.12.2020, number: 20/23).

Informed Consent: The informed consent was obtained.

\section{Authorship Contributions}

Surgical and Medical Practices: Ö.F.K., S.A., Concept: Ö.F.K., S.A., Design: Ö.F.K., Data Collection or Processing: Ö.F.K., A.K., Analysis or Interpretation: Ö.F.K., S.A., Literature Search: Ö.F.K., V.N., Writing: Ö.F.K., A.K., V.N., S.A.

Conflict of Interest: The authors declare that they have no conflict of interest.

Financial Disclosure: The authors declared that this study received no financial support.

\section{REFERENCES}

1. Klimo $P$ Jr, Schmidt MH. Surgical management of spinal metastases. Oncologist. 2004;9:188-96.

2. Ma Y, He S, Liu T, Yang X, Zhao J, Yu H, et al. Quality of life of patients with spinal metastasis from cancer of unknown primary origin: a longitudinal study of surgical management combined with postoperative radiation therapy. I Bone Joint Surg Am. 2017; 99:1629-39.

3. Vertebral Augmentation Involving Vertebroplasty or Kyphoplasty for Cancer-Related Vertebral Compression Fractures: A Systematic Review. Ont Health Technol Assess Ser. 2016;16:1-202.

4. Kassamali RH, Ganeshan A, Hoey ETD, Crowe PM, Douis H, Henderson J. Pain management in spinal metastases: the role of percutaneous vertebral augmentation. Ann Oncol. 2011;22:782-6.

5. Ozturk E. The results of paliative management with strontium-89 for painfull metastatic spinal tumors. J Turk Spinal Surg. 2007;18:17-22.
6. Munk PL, Rashid F, Heran MK, Papirny M, Liu DM, Malfair D, et al. Combined cementoplasty and radiofrequency ablation in the treatment of painful neoplastic lesions of bone. J Vasc Interv Radiol. 2009;20:903-11.

7. Clarençon $F$, Jean B, Pham HP, Cormier E, Bensimon G, Rose M, et al. Value of percutaneous radiofrequency ablation with or without percutaneous vertebroplasty for pain relief and functional recovery in painful bone metastases. Skeletal Radiol. 2013;42:25-36.

8. Gangi A, Dietemann JL, Schultz A, Mortazavi R, Jeung MY, Roy C. Interventional radiologic procedures with $\mathrm{CT}$ guidance in cancer pain management. Radiographics. 1996;16:1289-304; discussion 1304-286.

9. Amar AP, Larsen DW, Esnaashari N, Albuquerque FC, Lavine SD, Teitelbaum GP. Percutaneous transpedicular polymethylmethacrylate vertebroplasty for the treatment of spinal compression fractures. Neurosurgery. 2001;49:1105-14; discussion 1114-105.

10. Ersen O, Tuzun HY, Kilinc NS, Bilekli AB. Radiofrequency ablation plus vertebroplasty in the treatment of symptomatic vertebral hemangiomas without neurological deficit. I Turk Spinal Surg. 2020;31:85-7.

11. Orgera G, Krokidis M, Matteoli M, Varano GM, La Verde G, David V, et al. Percutaneous vertebroplasty for pain management in patients with multiple myeloma: is radiofrequency ablation necessary? Cardiovasc Intervent Radiol. 2014;37:203-10.

12. Wallace AN, Robinson CG, Meyer ], Tran ND, Gangi A, Callstrom MR, et al. The metastatic spine disease multidisciplinary working group algorithms. Oncologist. 2015;20:1205-15.

13. Hoffmann RT, Jakobs TF, Trumm C, Weber C, Helmberger TK, Reiser MF. Radiofrequency ablation in combination with osteoplasty in the treatment of painful metastatic bone disease. J Vasc Interv Radiol. 2008; 19:419-25.

14. Reyes M, Georgy M, Brook L, Ortiz O, Brook A, Agarwal V, et al. Multicenter clinical and imaging evaluation of targeted radiofrequency ablation (t-RFA) and cement augmentation of neoplastic vertebral lesions. J Neurointerv Surg. 2018;10:176-82.

15. Schaefer O, Lohrmann C, Markmiller M, Uhrmeister P, Langer M. Technical innovation. Combined treatment of a spinal metastasis with radiofrequency heat ablation and vertebroplasty. AJR Am J Roentgenol. 2003;180:1075-7.

16. Kim YJ, Lee JW, Park KW, Yeom J-S, Jeong HS, Park JM, et al. Pulmonary cement embolism after percutaneous vertebroplasty in osteoporotic vertebral compression fractures: incidence, characteristics, and risk factors. Radiology. 2009;251:250-9.

17. Wallace AN, Tomasian A, Vaswani D, Vyhmeister R, Chang $\mathrm{RO}_{\text {, }}$ Jennings JW. Radiographic local control of spinal metastases with percutaneous radiofrequency ablation and vertebral augmentation. AJNR Am J Neuroradiol. 2016;37:759-65.

18. Nakatsuka A, Yamakado K, Maeda M, Yasuda M, Akeboshi M, Takaki, $\mathrm{H}$, et al. Radiofrequency ablation combined with bone cement injection for the treatment of bone malignancies. J Vasc Interv Radiol. 2004; 15:707-12. 